\title{
LOS ILIRIOS Y ALBANESES EN LAS FUENTES LITERARIAS GRIEGAS Y ROMANAS
}

\author{
RICARDO BLANCO LÓPEZ \\ Instituto Egara (Terrassa) \\ rblanc22@xtec.cat
}

\section{RESUMEN}

La intención de este artículo es recopilar y analizar las fuentes literarias griegas y romanas más representativas que recogen información del pueblo ilirio y la mención a los albaneses como posible tribu iliria en las fuentes literarias griegas.

PALABRAS CLAVE: Ilirios, albaneses, fuentes literarias grecorromanas, etnografía antigua.

THE ILLYRIANS AND THE ALBANIANS IN GREEK AND ROMAN LITERARY SOURCES.

\section{ABSTRACT}

The purpose of this article is to compile and analyse the most representative Greek and Roman literary sources that give information about the Illyrian people, as well as the mention of the Albanians as a possible Illyrian tribe in the Greek and Roman literary sources.

KEYWORDS: Illyrians, Albanians, Greek and Roman literary sources, ancient ethnography.

\section{INTRODUCCIÓN}

Con este artículo se pretende aportar más indicios sobre la posible filiación étnica de los albaneses con los ilirios a través del estudio de las fuentes literarias griegas y romanas. En primer lugar, se hará un recorrido de la historia del pueblo ilirio a través de las fuentes literarias más representativas con la intención de encontrar algún pasaje que recoja información relacionada con el tema. A continuación, se destaca un pasaje de la obra Geografía del geógrafo griego Ptolomeo (II d.C.) que podría ser la primera mención de los albaneses en las fuentes literarias clásicas. Por otra parte, en este artículo se recoge también las opiniones de algunos especialistas en relación al tema de los albaneses.

LOS ILIRIOS: RECOGIDA Y ANÁLISIS DE LAS FUENTES LITERARIAS GRIEGAS Y ROMANAS

El historiador griego Heródoto (V a.C.) es el primer autor clásico que menciona en su obra Historia $(4,49,2)$ el nombre de Iliria, la cual está bañada por diferentes ríos y situada geográficamente a lo largo de la costa oriental del Adriático. 
“Desde Iliria corre hacia el norte el río Angro, que desemboca en la llanura Tribálica y en el río Brongo." ${ }^{1}$

Hay que esperar hasta la República Romana para que las fuentes literarias clásicas recojan información sobre el pueblo de los ilirios. El historiador griego Polibio (III-II a.C.) en su obra Historias menciona que la primera expedición ${ }^{2}$ de los romanos hacia Iliria fue en el siglo III a.C. Sobre esa época, los ilirios comenzaron a expansionarse por los territorios vecinos, y en su afán de conquista, atacaron y abordaron el barco donde viajaba el embajador romano. Este episodio provocó la ira de los romanos y como consecuencia el inicio de un conflicto con los romanos, hasta que, finalmente, Iliria fue conquistada y anexionada como provincia romana. El autor romano Cicerón ${ }^{3}$ (II-I a.C.), recoge en algunas obras suyas que la región de Iliria formaba parte de la República Romana.

“Así pues, la República tiene Macedonia, tiene Iliria, protege a Grecia; nuestras son las legiones, nuestra la infantería ligera, nuestra la caballería [...]" Cic., Phil. 10,6. 14. ${ }^{4}$

Es en los primeros tiempos de la época imperial cuando Iliria es dominada por completo, y por ello, la información que dan los autores clásicos ${ }^{5}$ sobre el pueblo de los ilirios es más precisa, como por ejemplo, el geógrafo griego Estrabón (I a.C. - I d.C.), que en el libro VII de su obra Geografía, describe con más exactitud la región de Europa situada al sur del Danubio; y el historiador romano Apiano (II d.C.) que recoge en el libro X dedicado íntegramente a la Iliria, de su obra titulada Historia Romana, su situación geográfica, origen mitológico de este pueblo, las tribus que formaban el pueblo ilirio y el enfrentamiento con los romanos y posterior dominio de éstos sobre la Iliria. Se destaca aquí, el mito del nacimiento del héroe Ilirio, epónimo de los ilirios.

“Y dicen que el país tomó el nombre a partir de Ilirio, el hijo de Polifemo, pues el cíclope Polifemo y Galatea tuvieron tres hijos: Celto, Ilirio y Gala, que emigraron desde Sicilia y gobernaron sobre los celtas, ilirios y gálatas, llamados así por su causa. Y es ésta la versión más plausible desde mi punto de vista, aunque hay muchos que cuentan otros muchos mitos." Ap. 10, 1.6

1 Traducción de C. Schrader en Biblioteca Clásica Gredos-RBA. Madrid, 2015. La llanura tribálica es la región del actual Belgrado; consecuentemente, el río Angro se identifica con el río Morova del sur (Juzna), y el río Brongo se identifica con el Morava (Zapadna), que desemboca al este de Belgrado.

${ }^{2}$ Pol., Hist, 1, 13.4.

${ }^{3}$ Cic. pro Aul., 97.

${ }^{4}$ Traducción de Mํ José Muñoz en Biblioteca Clásica Gredos-RBA. Madrid, 2016.

${ }^{5}$ Str. Geogr. 7, 5.3; Ap. Hist. Romana (sobre la Iliria), 16.

${ }^{6}$ Traducción de Antonio Sancho en Biblioteca Clásica Gredos. Madrid, 1995. 
La versión ${ }^{7}$ mitológica más generalizada, recoge que Ilirio es el más pequeño de los hijos de Cadmo y Harmonía. En cambio, Apiano recoge otra versión en su obra que atribuye a los amores de Polifemo y Galatea el nacimiento de tres hijos, entre los cuales está Ilirio. Cabe destacar que, en la versión más generalizada de dicho mito, la ninfa Galatea se muestra poco receptiva a los deseos amorosos del cíclope Polifemo.

"Los griegos consideran ilirios a los pueblos que habitan al otro lado de Macedonia y Tracia, desde Caonia y Tesprocia hasta el río Danubio. Ésta es la longitud del país, y su anchura comprende desde Macedonia y las montañas de Tracia hasta Panonia y el mar Adriático y las estribaciones de los Alpes." Ap. 10, 1.

No fue hasta la época romana que los límites de la Iliria estuvieron bien definidos limitando: al norte con el golfo Venético (territorio de los Vénetos), al sur con la región del Epiro griego, al oeste con el Mar Adriático y al este y sureste con la Tracia, Peonia y Macedonia.

El pueblo de los ilirios estaba formado, como era frecuente entre los pueblos indoeuropeos, por diferentes tribus que habitaban a lo largo de la costa adriática y tierras del interior. El historiador romano Apiano recoge los nombres de las diferentes tribus ilirias y añade, no siempre, una breve nota sobre la historia de cada tribu. Con los datos que proporciona Apiano, el profesor J.P. Mallory ha confeccionado un mapa con los límites de la Iliria y sus diferentes tribus.

Apiano incluye dentro del pueblo ilirio a los retios, nóricos y finalmente a los peonios o peones y su tribu más célebre, los agrianes. No obstante, cabe aclarar que los retios no eran una tribu iliria, aunque habitaban cerca del río Danubio; que los nóricos eran una tribu de origen germánico que limitaba con los ilirios; y que el pueblo peonio, ${ }^{8}$ cuyo origen aún es mesa de discusión, habitaba entre las cuencas de los ríos Axio y Estrimón y estaba formado por diversas tribus, de las cuales la más célebre era la de los agrianes, fama que viene

\footnotetext{
${ }^{7}$ Grimal (1981: 209; 287).

8 Blanco López, Ricard: (2002) «El poble peoni: parent dels troians», Faventia, 24/1, 45-53.

- (2003) «Las tribus peonias: doberos, peoples y siriopeonios a través de las fuentes literarias clásicas y bizantinas», Živa Antika (Antiquité Vivante), 53, fasc 1-2, 5-13.

- (2006) «Tribus peonias: los agrianes en el contexto histórico y geográfico de la Antigüedad», Živa Antika (Antiquité Vivante), 56, fasc 1-2, 5-17.

- (2007) «El pueblo peonio en la época romana: estudio de las fuentes literarias clásicas», Thracia, XVII, 151-158.

- (2012) «Tribus peonias: peonios originarios y leeos a través de las fuentes literarias clásicas y derrones en la numismática», Živa Antika (Antiquité Vivante), 62, fasc 1-2, 17-24.

- (2013) «La historia del pueblo peonio (XII-VI a.C): recogida y análisis de las fuentes literarias clásicas.», Fortunatae, 24, 23-35.

- (2017) De opos a limes: el concepto de frontera en el mundo antiguo y su recepción: El pueblo peonio a través de las fuentes literarias clásicas: de fronteras naturales a provincia romana. Escolar y Mayo Editores, Uned-Madrid, 83-89.
} 
desde época helenística, al formar parte del ejército de Alejandro Magno y de sus conquistas.

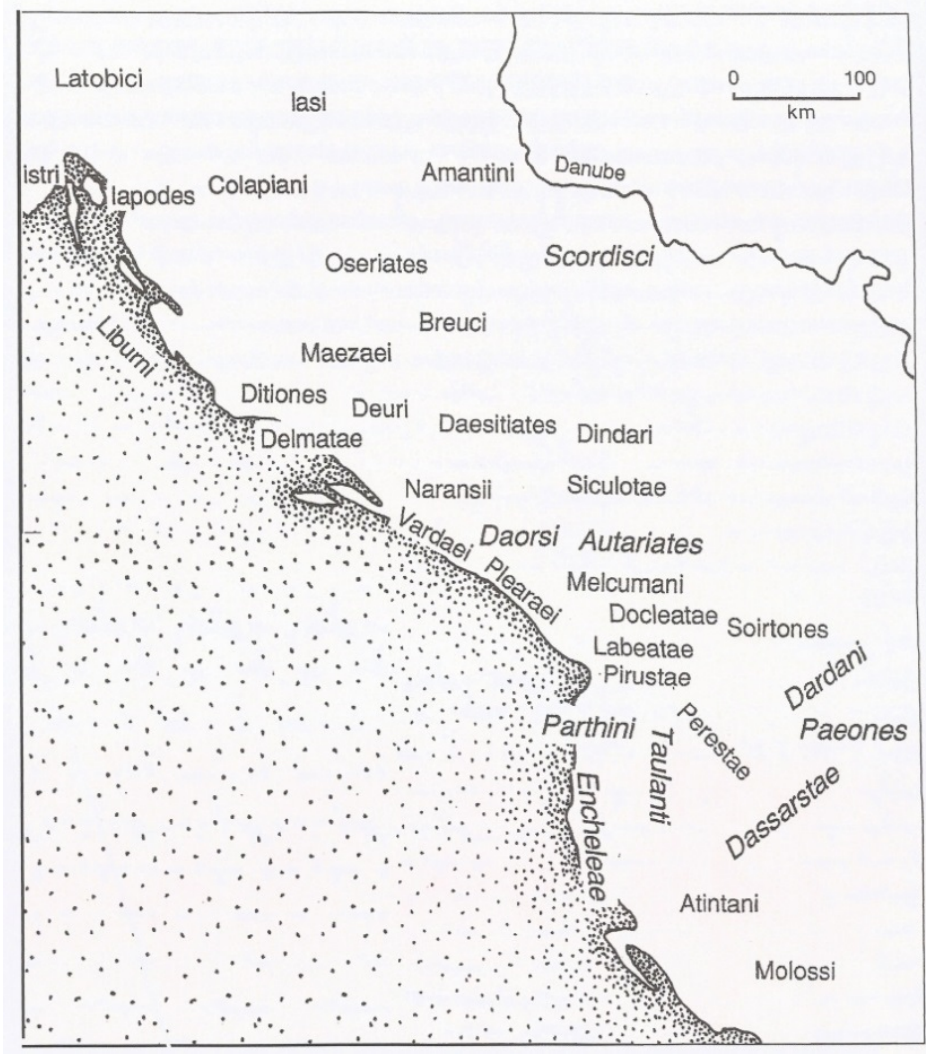

J.P. Mallory (1997), p. 90.

\section{LOS ALBANESES: RECOGIDA Y ANÁLISIS DE LAS FUENTES LITERARIAS GRIEGAS}

El geógrafo griego Ptolomeo (II d.C.) es el primer autor de época clásica que recoge el nombre 'A $\lambda \beta \alpha \nu \omega v$, como primera mención en las fuentes literarias clásicas al pueblo de los albaneses en su obra Geografía. ${ }^{9}$ Véase texto:

23. De los albanos (albaneses). Albano ciudad. 4641 12”.' Ptol. 2, 23. ${ }^{10}$

\section{CONSIDERACIONES FINALES}

El origen del pueblo albanés y, por tanto, la filiación o no a un grupo étnico y lingüístico específico es todavía tema de discusión. El indoeuropeista francés B. Sergent ${ }^{11}$ defiende el origen daco-misio del pueblo albanés; mientras que F. Bopp, uno de los fundadores de la Lingüística indoeuropea en el siglo XIX, ya reconoció al albanés como un grupo étnico y lingüístico independiente.

\footnotetext{
${ }_{9}$ Claudii Ptolomaei, Geographia I-III. Seguimos la edición de C.F.A Nobbe en Georg Olms Verlag, Hildesheim · Zurich · New York, 1990.

10 Traducción propia.

11 Sergent (1995).
} 
Otro posible origen de los albaneses que algunos especialistas defienden es el origen ilirio y, por lo tanto, la lengua albanesa derivaría de la antigua lengua iliria. F. Villar (1996: 313) sobre este posible origen ilirio dice: "Por una parte están los que, por motivos más históricos y de sentido común que específicamente lingüísticos, quieren ver en el albanés el heredero moderno del ilirio."

Estos motivos históricos y de sentido común, que manifiestan algunos especialistas, se refieren al hecho que los albaneses actuales ocupan una parte del territorio del antiguo pueblo ilirio ya que las fuentes históricas antiguas, bizantinas y medievales no recogen en ningún momento ninguna migración en la zona de un pueblo denominado albaneses. En contra de este origen ilirio se encuentran los argumentos lingüísticos: la fonética, el léxico y la toponimia, aunque este argumento tampoco es definitivo porque no se conservan suficientes textos en lengua iliria para refutar este posible origen ilirio de los albaneses.

Por lo tanto, la información que recoge el pasaje del geógrafo griego Ptolomeo es relevante porque podría ser la primera mención a los albaneses en las fuentes literarias clásicas, dado que Ptolomeo describe y sitúa geográficamente pueblos y ciudades de esta zona del litoral mediterráneo. Este argumento tiene más fuerza cuando se amplía este estudio del texto de Ptolomeo a las líneas anteriores donde se recoge también la mención a la tribu de los Taulantios y su ciudad Arnisa, ${ }^{12}$ entre otras.

20. De los Taulantios: Arnisa. 443 403.” Ptol. 2, 13.20.13

Los taulantios ${ }^{14}$ eran una tribu iliria situada al sur de la Iliria. Según el mito, Taulante es hijo de Ilirio, de él descienden los taulantios.

Para acabar, se podría decir que en la obra Geografía de Ptolomeo se recoge la mención a los albaneses y que, además, podrían ser una de las tribus del pueblo ilirio, documentada ya en el siglo II d.C. en las fuentes literarias clásicas.

12 Cf. nota 8.

13 Traducción propia.

${ }^{14}$ Ap. Hist. Rom. (sobre la Iliria), 2, 16.24. 


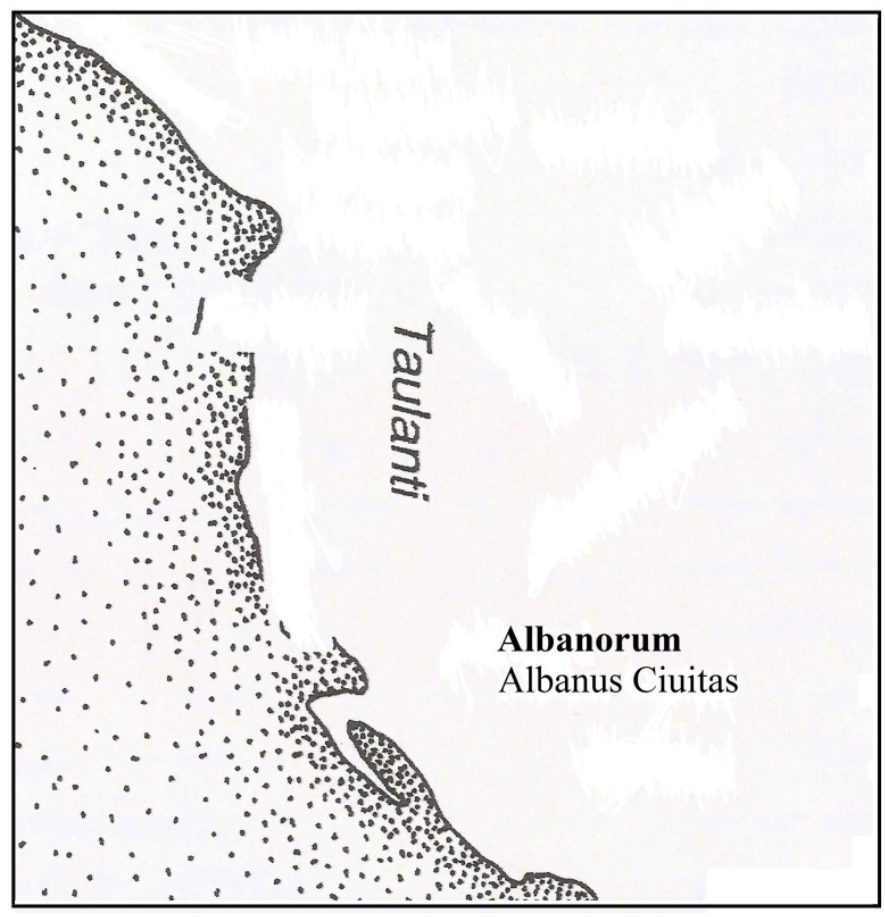

Mapa del autor

BIBLIOGRAFÍA

BADER, F. (1997), Langues Indo-européennes, Paris, CNRS Editions.

BOSCH-GIMPERA, P. (1980), Les Indo-Européens, problèmes archéologiques, Paris, Payot.

BUDINA, D. (1971), “L'apparttenance ethnique illyrienne des tribes épirotes”, Les Illyriens et la genèse des Albanais, 111-120.

CABEJ, E. (1964), "Einige Grundprobleme der älteren albanischen Sprachgeschichte", Studi Albanesi, 1, 69-89.

— (1970), "L'Illyrien et l'Abanais, questions de príncipe", Studi Albanesi, 7, 157-170.

Čović, B. (1986), Die Ethnogenese der Illyrier aus der Schicht der Vor- und Frühgeschichte. Ethnogenese Europäischer Völker, Stuttgart and New York, ed. W. Bernhard and A. Kandler-Pálsson, 55-74.

DEMIRAJ, S. (1994), L'albanais, in Les Indo-européennes, Paris, ed. F. Bader, - CNRS Editons, 221-232.

GiaCAlONe RAMAT, A. P. (1995), Las lenguas Indoeuropeas, Madrid, Catedra.

GRIMAL, P. (1981), Diccionario de Mitología Griega y Romana, Barcelona, Paidós.

HAMP, E. P. (1957), Albanian and Messapic, in Studies Presented to Joshua Whatmough, ed. E. Pulgram, The Hague, Mouton, 73-89.

— (1966), "The position of Albanian", in Ancient Indo-European Dialects, eds. H. Birnhaum and J. Puhvel, Berkeley and Los Angeles, University of California Press, 97-122.

HARMATTA, J. (1967), “Zum Illyrischen”, Acta Antiqua Academiae Scientiarum Hungaricae, $15,231-234$.

HulD, M. E. (1984), Basic Albanian Etymologies. Columbus, Ohio, Slavica.

JOKL, N. (1963), “Die Verwandschaftsverhältnisse des Albanischen zu den übrigen indogermanischen Sprachen", Die Sprache, 9, 113-156.

KATIČIĆ, R. (1964), “Illyrii propie dicti” Živa Antika, 13-14, 87-97.

— (1966), “Nochmals Illyrii propie dicti”, Živa Antika, 16, 241-244. 
- (1976), Ancient Languages of the Balkans, The Hague-Paris.

KRAHE, H. (1955-1964), Die Sprachen der Illyrien. 2 vols. Wiesbaden, Harrasswitz.

KRONASSER, H. (1962), "Zum Stand der Illyristik”, Linguistique Balkanique, 4, 5-23.

- (1965), "Illyrier und Illyricum", Die Sprache, 11, 155-183.

MALLORY, J.P. y ADAMS, D. Q, (1997), Encyclopedia of Indo-European Culture, LondonChicago, Fitzroy Dearborn Publishers.

MALLORY, J.P. (1997), À la recherche des Inodo-Européens, Langue, archéologie, mythe, France, Ed. Seuil.

MANN, S. E. (1977), An Albanian Historical Grammar. Hamburg, Helmut Buske.

MARTINET, A. (1997), De las estepas a los Océanos, Madrid, Gredos.

PISANI, V. (1937), "Il problema illirico", Panonia, 3, 276-290.

POLLO, S. y PUTO, A. (1974), Histoire de l'Albanie: des origines à nos jours, Roanne: Éd. Horvath.

POlOMÉ, E. C. (1966), “The position of Illyrian and Venetic" in Ancient Indo-European Dialects, eds. J. Puhvel and H. Birnhaum, Berkeley and Los Angeles, University of California, 59-76.

- (1982), "Balkan languages (Illyrian, Thracian and Daco-Moesian)", in The Cambridge Ancient History, vol. III, part 1, eds. J. Boardman et al., Cambridge, Cambridge University Press, 866-888.

RAdulesCU, M. M. (1984), “Illyrian, Thracian, Daco-Mysian, the Substratum of Romanian and Albanian" JIES, 12.

RENFREW, C. (1987-1988), Archaeology E Language, The puzzle of Indo-European Origins, New York, Cambridge University Press.

SERGENT, B. (1995), Les Indo-Européens: Histoire, langue, mythes, France, Payot.

StIPČEVIČ, A. (1977), The Illyrians, New Yersey, Noyes Press.

VILLAR F. (1996), Los indoeuropeos y los orígenes de Europa (Lenguaje e Historia), Madrid, Gredos.

WILKES, J. (1992), The Illyrians. Oxford, Blackwell. 